\title{
Cloning and evaluation of reference genes for quantitative real-time PCR analysis in Amorphophallus
}

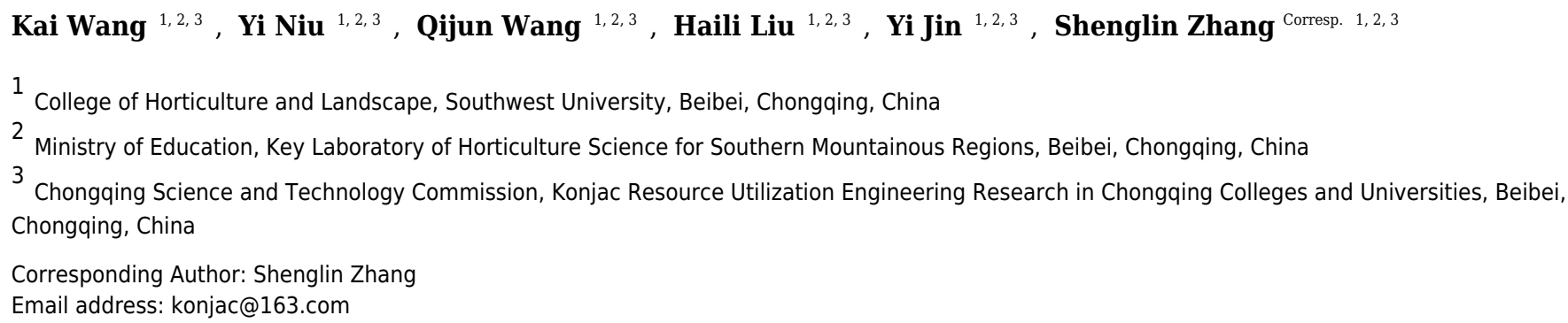

Quantitative real-time reverse transcription PCR (RT-qPCR) has been widely used in the detectionand quantification of gene expression levels because of its high accuracy, sensitivity, and reproducibility as well as its large dynamic range. However, the reliability and accuracy of RT-qPCR depends on accurate transcript normalization using stably expressed reference genes. Amorphophallus is a perennial plant with a high content of konjac glucomannan (KGM) in its corm. This crop has been used as a food source and as a traditional medicine for thousands of years. Without adequate knowledge of gene expression profiles, there has been no report of validated reference genes in Amorphophallus. In this study, nine genes that are usually used as reference genes in other crops were selected as candidate reference genes. These putative sequences of these genes Amorphophallus were cloned by the use of degenerate primers. The expression stability of each gene was assessed in different tissues and under two abiotic stresses (heat and waterlogging) in A. albus and A. konjac. Three distinct algorithms were used to evaluate the expression stability of the candidate reference genes. The results demonstrated that EF1-a, EIF4A, H3 and UBQ were the best reference genes under heat stress in Amorphophallus. Furthermore, EFI-a, EIF4A, TUB, and RP were the best reference genes in waterlogged conditions. By comparing different tissues from all samples, we determined that EF1- $\alpha$, EIF4A, and CYP were stable in these sets. In addition, the suitability of these reference genes was confirmed by validating the expression of a gene encoding the small heat shock protein SHSP, which is related to heat stress in Amorphophallus. In sum, EF1- $\alpha$ and EIF4A were the two best reference genes for normalizing mRNA levels in different tissues and under various stress treatments, and we suggest using one of these genes in combination with 1 or 2 reference genes associated with different biological processes to normalize gene expression. Our results will provide researchers with appropriate reference genes for further gene expression quantification using RT-qPCR in 
Amorphophallus. 
1

2

3

4

5

6

7

8

9

10

11

12

13

14

15

16

17

18

19

20

21

22

23

24

25

26

27

28

29

30

31

32

33

34

35

36

37

38

39

40

41

9

1

Title:

\section{Cover page}

Cloning and evaluation of reference genes for quantitative real-time PCR analysis in Amorphophallus

Authors:

Kai Wang, Yi Niu, Qijun Wang, Haili Liu, Yi Jin, Shenglin Zhang*

Affiliations:

College of Horticulture and Landscape, Southwest University, Chongqing 400715, PR China

Key Laboratory of Horticulture Science for Southern Mountainous Regions, Ministry of Education, Southwest University, Chongqing 400715, PR China

Konjac Resource Utilization Engineering Research in Chongqing Colleges and Universities, Chongqing 400715, PR China

*Corresponding author: Shenglin Zhang; Tel: +862368250732; fax: +862368250733; E-mail address: konjac@163.com.

2




\section{INTRODUCTION}

Gene expression analysis is an effective and widely used approach to elucidate transcriptional regulatory networks and identify novel genes (Thompson et al., 2015). In comparison with other techniques that are used to measure transcript abundance, quantitative real-time reverse transcription-PCR (RT-qPCR) has become the preferred method for gene expression studies because of its speed, sensitivity, and specificity (Bustin, 2000; Bustin et al., 2009; Nolan et al., 2006). There are many factors that affect the accuracy of RT-qPCR data, including amplification efficiency (Pfaffl, 2005) and RNA quality (Vermeulen et al., 2011). Selecting a suitable reference gene and using a set of standardized experimental conditions are among the most important factors for quantifying gene expression by RT-qPCR (Bustin et al., 2009; Hellemans et al., 2014). Suitable reference genes have been identified for many crops and especially for model plants (Dekkers et al.,2012; Czechowski et al., 2005; Itoh et al., 2016). Reference genes that are used as appropriate normalization genes usually have high copy numbers and relatively stable expression (Thellin et al., 1999). These genes are ubiquitously expressed and are

Ideal reference genes should be expressed stably in different environments, different tissues, different growth stages, and different experimental conditions, and their expression should not be significantly different between samples ( $\mathrm{Li}$ et al., 2005). However, an increasing number of studies have found that commonly used reference genes do not typically satisfy all these criteria: their expression typically shows large variations between different types of cells and tissues, different stages of organ development and cell proliferation, different culture conditions in vitro, and different experimental conditions (Lee et al., 2002; Hisbergues et al., 2003; Dheda et al., 2004; Zmienko et al., 2015). Selection of suitable reference genes largely depends on seeking specific reference genes with stable expression in each examined cell or tissue and each experimental condition (Hellemans et al., 2014).

In recent years, studies have selected reference genes for different experimental conditions in an increasing number of crops, such as watermelon (Kong et al., 2014), cotton (Wang et al., 2013), tomato (Løvdal et al., 2009), switchgrass (Huang et al., 2014), rice (Maksup et al., 2013), wheat (Paolacci et al., 2009), pearl millet (Saha et al., 2014), and Oenanthe javanica (Jiang et al., 2014). Many reference genes have been identified as suitable reference genes under specific experimental conditions. For instance, $A C T 7$ was the best reference gene in pearl millet and $O$. javanica (Jiang et al., 2014) under abiotic stress, EF1- $a$ was the most suitable reference gene in chrysanthemum aphid infestation (Gu et al., 2011) and TUA, UBI-ep, and EF1-a data could be used to normalize RT-qPCR data in cucumber (Wan et al., 2010).

Amorphophallus, a perennial herb in the family Araceae, genus Amorphophallus, is mainly found in India, the Indo-China Peninsula, south China (mostly in Yunnan province) and Southeast Asia (Gille et al., 2011). Its underground corm has abundant konjac glucomannan (KGM), and this species is the only crop that is able to produce abundant KGM in nature (Fang et al., 2004). KGM is a high-molecular-weight, water-soluble dietary fiber (Zhang et al., 2005) with a variety of clinical and health effects on the human body. Furthermore, some phenolics and alkaloids in Amorphophallus have a beneficial effect in the treatment of chronic diseases. Because of these properties, Amorphophallus is a rare and special vegetable and medicinal plant that has been widely grown in southwest China, and KGM is used in food, medicine, and other fields. In recent years, with the increase of the emphasis on health problems, the use of konjac flour as a health food and medicine has been more 
attentively studied. Overall, Amorphophallus, the only plant that can produce large amounts of KGM, is an important resource crop in Asia and throughout world. Interestingly, Amorphophallus is a typical shadedemanding plant, intolerant to heat damage and waterlogging, and flooding and high temperature are two important factors that significantly impact Amorphophallus growth. Understanding the expression level of genes associated with resistance and elucidating the expression patterns of some key regulatory genes would contribute to genetic improvement of Amorphophallus. However, as one of the main identification methods of gene determination, RT-qPCR requires stable reference genes. Therefore, verification of stable reference genes in Amorphophallus is necessary. So far, due to limitations in genomic data, there have been no studies that screened for suitable reference genes in Amorphophallus. In this study, we selected 9 candidate reference genes that are commonly used in other crops: glyceraldehyde-3-phosphate dehydrogenase (GAPDH), elongation factor 1- $\alpha$ $(E F 1-a)$, the eukaryotic initiation factor 4A (EIF4A), H3.2 histones (H3), cyclophilin (CYP), $\beta$-actin (ACTB), $\beta$ tubulin (TUB), ubiquitin (UBQ), and ribosomal protein L16 (RP), (Yang et al., 2014; Huang et al., 2014: Gopaulchan et al., 2013). In addition, the expression levels of the SHSP gene in leaves, which is upregulated in response to heat stress in plants, were verified to determine the suitability of the candidate reference genes. The purpose of this study is to determine whether the candidates are suitable reference genes under different conditions by comparing the expression stability of these genes in Amorphophallus, which would provide a theoretical basis for the identification of the expression of target genes in related regulatory networks.

\section{MATERIALS AND METHODS}

\section{Plant materials and treatments}

Two types of cultivated species (Amorphophallus albus and Amorphophallus konjac) with a high konjac glucomannan (KGM) content and good quality from the Xiema resource nursery (Xiema, Beibei, Chongqing, $P R$ China) were used as experimental materials. The corms were planted in pots containing soil and peat (2:1, $\mathrm{V} / \mathrm{V}$ ), cultured in a greenhouse and irrigated once every 7 days. After the blades were fully extended, the plants were treated with a simulated high temperature $\left(40^{\circ} \mathrm{C}\right)$ or waterlogging $(2.5 \mathrm{~cm}$ above the soil surface), and the leaves were harvested after $0 \mathrm{~h}, 2 \mathrm{~h}, 4 \mathrm{~h}, 8 \mathrm{~h}$, and $1 \mathrm{~d}$ of exposure (Gu et al., 2011). Different tissue samples (leaves, roots, and corms) were harvested from the same plant after being excavated from the pot and rinsed with distilled water. The materials for verifying the expression profile of $S H S P$ were treated at $42^{\circ} \mathrm{C}$ and harvested at $0 \mathrm{~h}, 1 \mathrm{~h}, 2 \mathrm{~h}, 4 \mathrm{~h}$, and $8 \mathrm{~h}$. All samples were immediately frozen in liquid nitrogen after harvest and stored at $80^{\circ} \mathrm{C}$ prior to use.

\section{RNA isolation and first-strand cDNA synthesis}

Total RNA was extracted from Amorphophallus leaves using the ZH120 Quick RNA Islation Kit (Waryong, Beijing, China). RNA was treated with RNase-free DNase I (Waryong, Beijing, China). Total RNA from roots and ground corms was extracted by the pine method (Chang et al., 1993; Gille et al., 2011). The concentration and contaminants were measured using a NanoDropTM 2000 spectrophotometer (Thermo Scientific, USA), and only samples with an OD260/280 between 1.8 and 2.0 and OD260/230>2.0 were used for cDNA synthesis. The quality and integrity of total RNA were verified by $1 \%$ agarose gel electrophoresis. First-strand cDNA synthesis was conducted by using a PrimeScript TM RT reagent Kit RR047A with gDNA Eraser (TaKaRa, Japan) and generated by using random hexamers. One microgram of total RNA from each sample was used in reverse 
121

122

123

124

125

126

127

128

129

130

131

132

133

134

135

136

137

138

139

140

141

142

143

144

145

146

147

148

149

150

151

152

153

154

155

156

157

158

transcription reactions according to the manufacturer's instructions. The synthesized cDNAs were diluted to 25fold for RT-qRCR analyses.

\section{Gene cloning}

Degenerate primers of 8 candidate reference genes were designed based on conserved regions of homologous sequences of different monocots, such as Anthurium andraeanum, Phoenix dactylifera,

Elaeis guineensis, and Musa acuminata. The accession numbers from GenBank of 4 monocots are shown in

Table 1. The accession numbers of the primer sequences are listed in Table 2 . The amplified PCR products were A-T cloned into the pEASY-T1 simple vector, and then, the products were transformed into T1 competent cells. The pEASY-T1 simple vector and T1 competent cells were used with a pEASY-T1 simple cloning kit (Transgen, Beijing, China). Positive colonies were identified using colony PCR. The M13 forward and reverse primers were used to recover polymorphisms of the amplification results. Bacterial liquid cultures of positive clone products were sequenced by the Beijing Genomics Institute (BGI, China), and the sequences were identified as the candidate homologous reference genes using NCBI BLAST (Table 3). All of the sequences of the 8 candidate reference genes as well as the published $R P$ sequences (254998327) are shown in Seq S1.

\section{RT-qPCR assay}

RT-qPCR reactions were executed in 96-well plates using the Bio-Rad CFX96 Real-Time PCR system (BioRad, USA) and SsoFast EvaGreen Supermix (Bio-Rad, USA). The total volume comprised 4 ng of cDNA template, $0.2 \mu \mathrm{M}$ reverse primer, $0.2 \mu \mathrm{M}$ forward primer, $5 \mu \mathrm{L}$ of SYBR Green mix, and $\mathrm{ddH}_{2} \mathrm{O}$ to $10 \mu \mathrm{L}$. RTqPCR reactions were conducted using the following parameters: $95^{\circ} \mathrm{C}$ for $30 \mathrm{~s}$ followed by 40 cycles of $95^{\circ} \mathrm{C}$ for $5 \mathrm{~s}$ and $55-65^{\circ} \mathrm{C}$ for $5 \mathrm{~s}$. At the end of the process, the specificity of the amplification was tested using melting curve analysis from 65 to $95^{\circ} \mathrm{C}$ with a $0.5^{\circ} \mathrm{C}$ increase in temperature at each step. Each RT-qPCR reaction set included water as a negative no-template control for each primer pair. To obtain more reliable experimental results, each PCR assay was conducted in triplicate (technical replicates).

\section{Data analysis}

The methods commonly used to analyze the stability of reference genes are geNorm (Vandesompele et al., 2002), BestKeeper (Pfaffl et al., 2004), and NormFinder (Andersen et al., 2004), which are based on different computer algorithms to rank candidate reference genes under different experimental conditions (De Spiegelaere et al., 2015). The geNorm, BestKeeper, and NormFinder programs that were used to calculate the stable values were downloaded for experimental analysis (e.g., geNorm version 3.5 [http://medgen.ugent.be/ jvdesomp/genorm/], BestKeeper version 1 [http://www.gene-quantification.de/bestkeeper.html], NormFinder version 0.953 [http://www.mdl.dk/publicationsnormfinder.htm]).

The expression levels of the candidate reference genes were measured according to their quantification cycle $(\mathrm{Cq})$ values. For geNorm and NormFinder, the raw $\mathrm{Cq}$ values were converted to the required data using the formula: $2^{-\Delta \mathrm{Cq}}(\Delta \mathrm{Cq}=$ each corresponding $\mathrm{Cq}$ value-minimum $\mathrm{Cq}$ value; Liu et al., 2012). The geNorm algorithm was used to further determine the expression stability of the candidate reference genes by calculating the average expression stability value $(\mathrm{M})$ and pairwise variation $(\mathrm{V})$ between all pairs of genes. The ranking of candidate reference genes is based on those with lower $\mathrm{M}$ values. In addition, the BestKeeper algorithm used the untransformed $\mathrm{Cq}$ values to analyze stability. 


\section{Normalization of SHSP gene}

The gene expression levels of $S H S P$ were quantified at different time points under heat treatment using the best four reference genes (EF1-a, EIF4A, H3, and, $U B Q$ ) separately and a combination of multiple reference genes $(E F 1-a+H 3, E F 1-a+U B Q$, and $E F 1-a+H 3+U B Q)$. Two traditional reference genes (ACTB and GADPH) were also selected for normalization to control for different normalization factors. The software qBasePlus version 3.0 (http://www.biogazelle.com/) was downloaded for these calculations (Hellemans et al., 2007).

\section{RESULTS}

\section{Verification of the primer specificity and PCR amplification efficiency}

Specific primers for the reference genes and SHSP were designed using Primer3Plus (Untergasser et al., 2007; $\mathrm{http}: / /$ primer3plus.com/) based on the results of sequencing and the published ribosomal protein $(R P)$ sequences of Amorphophallus. The product sizes of the 9 candidate reference genes and SHSP amplified by specific primers were between 100-200 bp in length. Each primer pair was evaluated by the presence of a single peak in melting curve analysis (Fig S1A) and a single, distinct band on a 3\% agarose gel (Fig S1B). The gene-specific PCR amplification efficiency $(E)$ and correlation coefficient $\left(R^{2}\right)$ were calculated using a standard curve in which another replicate was performed using a standard curve generated by 10 -fold serial dilutions of gel-extracted PCR products. The amplification efficiency $(E)$ was calculated as follows: $E=\left(10^{-1 / s_{l o p e}}-1\right) \times 100 \%$ (Pfaffl, $2001)$. Only primers with an ideal value range $(110 \% \geq E \geq 90 \%)$ and correlation coefficient $\left(\mathrm{R}^{2} \geq 0.99\right)$ were used for subsequent experiments. The primer sequences and amplification characteristics, including the $T m$, length, efficiency, and $R^{2}$, are shown in Table 4. The PCR amplification efficiencies $(E)$ of nine candidate reference genes and SHSP were between $92.8 \%$ and $109.5 \%$. Standard curve regression equation correlation coefficients $\left(R^{2}\right)$ were between 0.990-0.999, which demonstrated a strong linear relationship.

\section{Cq values of candidate reference genes}

The raw $\mathrm{Cq}$ values of 9 candidate reference genes ranged from $18.73(R P)$ to 34.78 ( $A C T B$; Table $\mathrm{S} 1$ ), and the mean $\mathrm{Cq}$ value was used for further analysis. The mean $\mathrm{Cq}$ values of the reference genes were between 22.78 $(R P)$ and $27.96(T U B)$. The threshold fluorescence for $T U B$ was slightly higher than that of the other genes, indicating that $T U B$ had a low level of expression. In general, there were large variations in the expression levels of each of the 9 reference genes (Fig 1).

\section{geNorm analysis}

geNorm is a Microsoft-based VBA macro software that was developed by Vandesompele et al in 2002 (Vandesompele et al., 2002). The basic principle is that the ratio of the expression levels of two ideal reference genes under any experimental conditions or cells should be identical in all samples, keeping the calculated $\mathrm{M}$ value of a single gene as low as possible. In addition, an increasing number of studies have found that using two or more reference genes contributes to correct system deviation and obtaining more reliable results (Bustin et al., 2009; Vandesompele et al., 2002). Although geNorm can use standardized factors to pair differences, obtaining a lower threshold is preferable. 
We ranked the 9 candidate reference genes in 7 sets according to their expression stability values from low to high (Table 5). The threshold of the $\mathrm{M}$ value was 1.5; genes with an $\mathrm{M}$ value under 1.5 could be considered to be reference genes. $E F 1-a$ and $E I F 4 A$ were two of the best three reference genes in all sets, with values under the threshold in each case. In $A$. konjac heat-treated samples, the values of all of the candidate reference genes were under the threshold value, and $H 3$ had the lowest value $(\mathrm{M}=0.78) . U B Q$ performed well under heat stress in all heat-treated samples. Under waterlogged conditions, $T U B$ was the highest-ranked gene in the two species besides $E F 1-a$ and $E I F 4 A$, and 9 and 5 candidate reference genes could be regarded as reference genes based on their $\mathrm{M}$ values in $A$. albus and $A$. konjac, respectively. In a comparison of the expression of the 9 candidate reference genes across different tissues, only EF1- $a$ and $E I F 4 A$ were under the threshold value in the two species of Amorphophallus. Although $U B Q$ was the best candidate reference gene for $A$. albus, it was unstable in $A$. konjac. The M value of CYP was above 1.5 in A. konjac, but it ranked highly in the two species across different tissues. Therefore, we could regard it as an available additional reference gene across different tissues. "Total" contained all test samples, and EIF4A and EF1- $a$ were the best two reference genes in the total set. The values of $U B Q$ and $H 3$ were also under 1.5. The two most stable genes calculated by geNorm at each step during stepwise exclusion of the least stable reference gene are shown in Fig 2. Starting from the least stable gene at the left, the genes are ranked according to increasing expression stability, ending with the two most stable genes on the right. In general, EIF4A and EF1- $a$ showed remarkable stability in all sets. At the same time, $H 3$ and $U B Q$ under heat stress, $T U B$ under waterlogging, and $C Y P$ across different tissues were also expressed stably. In order to avoid using different genes belonging to the same biological process as reference genes, we excluded EIF4A and repeated the geNorm analysis. The results showed that EF1-a was still one of the stable ones in all sets (Fig 3).

Furthermore, to determine the optimal number of reference genes required for effective normalization, pairwise variation $(\mathrm{Vn} / \mathrm{Vn}+1)$, which is required for normalization between sequential normalization factors (NFs), was introduced by geNorm. All of the results of pairwise variation are illustrated in Fig 4. The cut-off value set by the algorithm is 0.15 , below which the inclusion of an additional reference gene is not required. For example, V2/3 of A. konjac in heat stress and V4/5 in A. albus under waterlogging were under the cut-off values, which indicated that 2 and 4 reference genes were required for more reliable normalization in these two conditions, respectively. While the 0.15 threshold was not met in the other samples, the geNorm developers emphasized in the user manual, that the proposed threshold of 0.15 must not be taken as a strict cutoff. The cut-off value was set only to offer guidance for determining the optimal number of reference genes. Therefore, they recommend that using only the 3 best reference genes is, in most cases, a valid normalization strategy and results in a much more accurate and reliable normalization compared to the use of only a single reference gene.

\section{NormFinder analysis}

Claus et al. compiled the NormFinder program in 2004, and the principle of the program is similar to that of geNorm. NormFinder generates a stable value for gene expression, then sorts gene expression in ascending order according to the stable value (Andersen et al., 2004). The gene with the lowest stable value is the most stable reference gene. However, this program has the drawback that it identifies only a single best reference gene.

The results calculated by NormFinder were similar to those calculated by geNorm. All of the values, ranked from low to high, are shown in Table 6. The lower the value, the higher the stability. In A. albus under heat stress, EF1- $a$ was the best reference gene, followed by EIF4A. In heat-treated A. konjac, $H 3$ was the best 
reference gene, followed also by EIF4A. Under waterlogging conditions, the results showed that $E F 1-a$ and $E I F 4 A$ were the best two reference genes in the two species. Additionally, $U B Q$ and $R P$ performed well across different tissues in A. albus based on the results calculated by NormFinder. In the total set, EIF4A and EF1-a showed remarkable expression stability in the two species of Amorphophallus. Overall, EIF4A and EF1-a performed very well in all sets and were identified as the best two reference genes in 5 sets.

\section{BestKeeper analysis}

BestKeeper software was written by Pfaffl et al in 2004. The data were entered into the BestKeeper Excel file. Then, BestKeeper calculated the standard deviation (SD) and coefficient of variance (CV) of each gene (Pfaffl et al., 2004). The candidate reference gene with the lowest coefficient of variance and standard deviation $(\mathrm{CV} \pm \mathrm{SD})$ was considered to be the best reference gene. Any reference gene with a $\mathrm{SD}>1$ was excluded because gene expression was not consistent in all samples. The advantage of BestKeeper software is that it is not only able to analyze the stability of reference genes, but it can also compare the expression levels of target genes.

The results of BestKeeper analysis were different from those of the other two programs which many researches had drew similar conclusions (Lin et al., 2014; Qi et al., 2016). This may be because the principle of this algorithm differs from that of the others. Lower $\mathrm{CV}$ values represent higher stability. EIF4A was the best reference gene under heat stress in the two species of Amorphophallus, and ACTB and EF1- $\alpha$ ranked second in A. albus and $A$. konjac, respectively. In the waterlogging sets, even though EIF4A performed well in A. albus, it was identified as the worst reference gene in A. konjac. At the same time, EF1- $\alpha$ was one of the least stable reference genes under waterlogging in both species of Amorphophallus. Across different tissues, CYP, EF1- $\alpha$, and $E I F 4 A$ were ranked the same and were the best three genes in both species. In total, $H 3, T U B$, and $U B Q$ were ranked above $E F 1-\alpha$ and $E I F 4 A$, even though $E F 1-\alpha$ and $E I F 4 A$ were ranked as unstable in other sets and were even the worst two genes in the waterlogging treatment of $A$. konjac. The stability of these two genes could be better than others when $\mathrm{SD} \leq 1$ was taken into consideration. In fact, this algorithm does not consider internal differences between different plants. The calculated results are only references for selecting reference genes. The ranking is shown in Table 7.

\section{Evaluation by normalizing of $\boldsymbol{S H S P}$}

Small heat shock proteins (SHSP) are important proteins in plants that function as molecular chaperones (JaKob et al., 1993). SHSP genes in plants are involved in resistance to abiotic stress and are rapidly induced under heat stress (Sun et al., 2002). The sequences of a SHSP gene from two species were cloned and are shown in Seq S1. The relative expression levels of SHSP analyzed using 9 different normalization factors are shown in Fig 5. The results revealed that the trends of SHSP expression were similar by using different normalization factors. However, differences were observed at $1 \mathrm{~h}, 2 \mathrm{~h}$, and $8 \mathrm{~h}$ and the relative expression using the identified reference genes showed almost identical results. The relative expression patterns of normalized by EIF4A and EF1- $a$ were more similar than $U B Q$ and $H 3$. When $A C T B$ and $G A D P H$ were used as reference genes, the expression of SHSP at these time points were significantly different from the results using identified stable genes in two species based on the results of student's T test. Lower sum of squares of deviations (SS) value indicated the data was closer to the expected. The result showed SS values of 3 normalization combinations were lower than these of single identified stable reference genes.

\section{DISCUSSION}

Amorphophallus, a poorly studied crop, is increasingly being studied because it can produce a large amount of 
274

275

276

277

278

279

280

281

282

283

284

285

286

287

288

289

290

291

292

293

294

295

296

297

298

299

300

301

302

303

304

305

306

307

308

309

310

311

312

313

314

the soluble dietary fiber konjac glucomannan (Fang et al., 2004). Dietary fiber is a complex mixture and is subdivided into soluble and non-soluble fiber (Chawla et al., 2010). Because it has good colloidal properties and excellent physiological functions, soluble dietary fiber has been widely used in food, medicine, industry, and other fields (Schneeman et al.,1986; Prosky et al., 1987; Farvid et al., 2016). KGM is a type of soluble dietary fiber with a high molecular weight and strong hydrophilic properties, and it has high therapeutic and medical value (Zhang et al., 2005). When used in food and ingested in the human digestive tract, $K G M$ contributes to healthier digestion and the excretion of solid waste (Arvill et al., 1995; Kaats et al., 2015). Studies have also shown that $K G M$ and some alkaloids in Amorphophallus have inhibitory effects on many diseases (Doi et al.,1979; Fan et al., 2008; Wu et al., 2011). Current transcriptome data for Amorphophallus have been deposited in the NCBI database, and these data accelerate the progress of studies on the important genes and in the molecular breeding of this species (Gille et al., 2011; Zheng et al., 2013). Important genes related to resistance (such as heat stress, waterlogging and other stresses) and agronomic properties could be identified by exploiting the transcriptome data and through other methods.

Gene expression analysis plays a significant role in identifying the expression profile and function of these genes (Huggett et al., 2005; Itoh et al., 2016). RT-qPCR is a preferred method to study gene expression because of its unique advantages (Bustin, 2009). However, without validating stable reference genes, the results of RTqPCR data lack credibility (Hellemans et al., 2014). In other words, the stability of reference gene expression is an elementary prerequisite for normalizing the expression profiles of target genes. Although stable reference genes are established in many crops, there have been no studies on reference genes in Amorphophallus.

The screening of reference genes in this study was carried out using different tissues and two main abiotic stresses that seriously influence the yield and quality of Amorphophallus. Waterlogging is the main factor that causes soft rot in Amorphophallus. In addition, by using different tissues, we evaluated the expression stability of the candidate reference genes across leaves, roots, and tubers under a wide range of experimental treatments.

Nine candidate reference genes whose homologs have been commonly used as reference genes in many plants were assessed simultaneously under various conditions using three distinct statistical algorithms: geNorm, NormFinder and BestKeeper. The results were mainly based on the geNorm algorithm and were further validated by NormFinder and BestKeeper. Integrating the specific identification results calculated by different algorithms, $E F 1-a, E I F 4 A, H 3$, and $U B Q$ were the four most stably expressed reference genes under heat treatment. For waterlogging stress experiments, $E F 1-a$, EIF4A, and $T U B$ were more stably expressed than the others. In different tissues, $E F 1-a, E I F 4 A$, and $C Y P$ showed the most stable expression. Overall, $E F 1-\alpha$ and $E I F 4 A$ were the best two candidate reference genes. The traditional two reference genes $A C T B$ and $G A D P H$ had large differences in expression levels between individuals. The results illustrated the necessity of validating reference genes in Amorphophallus.

For a long time, $A C T B$ and $G A D P H$ have been regarded as suitable reference genes, and their stable performance in many crops has been confirmed ( $\mathrm{Li}$ et al., 2014; Wang et al., 2013). Additional studies revealed that the stability of these two genes was lower than that of other genes (Gu et al., 2011; Martins et al., 2016). However, compared to our data on gene expression and results of SHSP expression normalization, we do not recommend using them as reference genes under the conditions we tested.

Even though some candidate genes, such as $H 3, T U B, U B Q$, and $C Y P$, showed stable expression in a single set, they were generally less stable in other sets in our study. These genes should only be used as reference genes under certain experimental conditions or in certain organisms. In previous studies, these genes also showed stable 
expression in several species. For instance, $H 3, A C T B$ and $U B Q$ have been used as internal controls for the analysis of RT-qPCR in cotton (Wang et al., 2013; Huang et al., 2011). In maize, TUB was one of best reference genes for gene expression (Lin et al., 2014). UBQ2 was validated as one of most suitable reference genes across all tested samples in banana fruit (Chen et al., 2011), and CYP was one of the best scoring genes in Vitis vinifera (Borges et al., 2014). In Amorphophallus, we suggest that these genes can be used as internal controls under certain experimental conditions and may lead a reliable result when combining them with EF1-a or EIF4A.

In our study, EF1-a and EIF4A showed high stability across all treatments in two species of Amorphophallus and were identified as the best two reference genes in many sets. In fact, many studies have shown that EF1- $a$ and EIF4A were stable in other monocots when used as reference genes. They have been selected as reference genes in perennial ryegrass (Lolium perenne L.), switchgrass (Panicum virgatum), and African oil palm (Elaeis guineensis) under different abiotic stresses (Huang et al., 2014; Gimeno et al.,2014; Xia et al., 2014). These species are typical monocots and are closely related to Amorphophallus. It has been shown that $E F 1-a$ and $E I F 4 A$ are stably expressed in many monocots. For example, one recent study showed that $E F 1-\alpha$ and $E I F 4 A$ were the most stable genes in different tissues of pearl millet (Reddy et al., 2015). Additionally, EF1$a$ had stable expression in foxtail millet (Setaria italica L.) and maize (Kumar et al., 2013; Lin et al., 2013). It could be that the stable expression of these genes is related to the role they play in biological metabolic pathways, as both proteins are involved in protein synthesis. Elongation factors are mainly responsible for the initial steps of protein synthesis, and eukaryotic initiation factors promote polypeptide chain extension during mRNA translation (Berchtold et al.,1993; Sonenberg et al., 2003). This may be the main reason why EF1- $a$ and EIF4A have similar expression in many species.

However, we were concerned that selecting multiple genes that participate in related biological processes may result in inaccurate results. geNorm algorithm works based on the assumption that the expression ratio of two ideal internal control genes is identical in all samples, regardless of the experimental conditions or cell type. This means that the absolute expression levels of these genes can change between conditions, but the ratio would be maintained. Variations of the absolute levels of each of the genes would likely reflect technical variability. This approach, however, only holds if the chosen genes belong to different functional classes; otherwise, one may be simply scoring co-regulation and may incorrectly assume that two genes are stably expressed and are appropriate reference genes, when in fact they may be responding to the treatment, but as they are part of the same process, they may be responding coordinately. When Vandesompele et al. developed this algorithm, they mentioned that special attention should be paid to selecting genes that belong to different functional classes, which significantly reduces the chance that genes might be co-regulated (Vandesompele et al., 2002). To avoid the use of two reference genes that are related to the same biological process, we supposed that excluding one of them and adding 1 or 2 reference genes related to different biological processes could effectively normalize the relative expression levels of the target genes in Amorphophallus. To verify this conjecture, we excluded EIF4A and repeated geNorm analysis, and analyzed the expression of the SHSP gene by designing different normalization combinations without EIF4A in Amorphophallus under heat stress.

The results calculated by geNorm revealed that EF1- $a$ was still one of the most stable reference genes. It probably behaves as a stably expressed gene and it is not because it is being co-expressed with another gene due to being part of the same biological process. In addition, the normalized result confirmed that the relative expression of $S H S P$ was not significantly different when EF1-a, EIF4A, H3, or UBQ was used as a single reference gene in normalizing the gene expression profile under heat stress. Highly similar expression level of 
356

357

358

359

360

361

362

363

364

365

366

367

368

369

370

371

372

373

374

375

376

377

378

379

380

381

382

383

384

385

386

387

388

389

390

391

392

393

394

SHSP normalized by EF1- $a$ and EIF4A suggested the presence of the co-expression of them. Although our "best genes" are functionally related, the third and fourth-ranked "good genes" also provided similar results compared with the two "best genes", which further supported the accuracy of the results calculated by three algorithms and the stability of the best four reference genes. The expression profiles of $S H S P$ were in almost perfect agreement when normalized by three combinations ( $E F 1-a+H 3, E F 1-a+U B Q$, and $E F 1-a+H 3+U B Q)$. These results showed that almost no difference was found when a single identified stable reference gene was used, and using one best reference gene sometimes can obtain accurate result in RT-qPCR normalization. However, the result that 3 combinations had lower SS value probably indicate that the normalization by multiple reference genes is closer to the actual expression. Furthermore, the strategy used to select combinations of reference genes also had impact on the final results. The combination should avoid these co-regulated genes with biological processes and be evaluated by geNorm. If selected candidate genes simply vary too much to be useful in a practical manner, reliable results cannot be obtained irrespective of how many reference genes are selected.

\section{CONCLUSION}

In the present study, the expression of nine candidate reference genes in Amorphophallus under two major stresses and across different tissues was compared and evaluated to identify stable reference genes for gene expression studies. Among them, EF1- $a$ and EIF4A appeared to be the two most appropriate reference genes. Integrating the analyses by three algorithms with normalization of SHSP expression, we recognized that a single reference gene may normalize the expression well under some conditions in RT-qPCR. But the result of using multiple reference genes are more credible. It is indispensable to select reference genes in a practical manner based on the specific experimental conditions and avoiding using multiple genes that participate in related biological processes. These results will provide useful information to profile the gene expression of resistance and quality-related in Amorphophallus.

\section{REFERENCES}

Andersen C, Jensen J, Orntoft T. 2004. Normalization of real-time quantitative reverse transcription-PCR data: a model-based variance estimation approach to identify genes suited for normalization, applied to bladder and colon cancer data sets. Cancer Research 64:5245-5250 DOI 10.1158/0008-5472.CAN-04-0496.

Arvill A, Bodin L. 1995. Effect of short-term ingestion of konjac glucomannan on serum cholesterol in healthy men. The American journal of clinical nutrition 61(3): 585-589.

Berchtold H, Reshetnikova L, Reiser CO, Schirmer NK, Sprinzl M, Hilgenfeld R. 1993. Crystal structure of active elongation factor Tu reveals major domain rearrangements. Nature 365: 126-132 DOI $10.1038 / 365126 \mathrm{a} 0$.

Borges AF, Fonseca C, Ferreira RB, Lourenço AM, Monteiro S. 2014. Reference gene validation for quantitative RT-PCR during biotic and abiotic stresses in Vitis vinifera. PLoS ONE 9(10): e111399 DOI 10.1371/journal.pone.0111399.

Bustin SA. 2000. Absolute quantification of mRNA using real-time reverse transcription polymerase chain reaction assays. Journal of molecular endocrinology 25(2): 169-193 DOI 10.1677/jme.0.0250169.

Bustin SA, Benes V, Garson JA, Hellemans J, Huggett J, Kubista M, Mueller R, Nolan T, Pfaffl MW, Shipley GL, Vandesompele J, Wittwer CT. 2009. The MIQE guidelines: minimum information for publication of quantitative real-time 
PCR experiments. Clinical chemistry 55(4): 611-622

DOI 10.1373/clinchem.2008.112797.

Chang S, Puryear J, Cairney J. 1993. A simple and efficient method for isolating RNA from pine trees. Plant molecular biology reporter 11(2): 113-116 DOI 10.1007/BF02670468.

Chen L, Zhong H, Kuang J, Li J, Lu W, Chen J. 2011. Validation of reference genes for RT-qPCR studies of gene expression in banana fruit under different experimental conditions. Planta 234(2): 377-390

DOI 10.1007/s00425-011-1410-3.

Chawla R, Patil GR. 2010. Soluble dietary fiber. Comprehensive Reviews in Food Science and Food Safety 9(2): 178-196 DOI 10.1111/j.1541-4337.2009.00099.x.

Czechowski T, Stitt M, Altmann T, Udvardi MK, Scheible W-R. 2005. Genome-wide identification and testing of superior reference genes for transcript normalization in Arabidopsis. Plant physiology 139(1): 5-17 DOI 10.1104/pp.105.063743.

Dekkers B J W, Willems L, Bassel G W, van Bolderen-Veldkamp RM, Ligterink W, Hilhorst HW, Bentsink L.2012. Identification of reference genes for RT-qPCR expression analysis in Arabidopsis and tomato seeds. Plant and Cell Physiology 53(1): 28-37 DOI 10.1093/pcp/pcr113.

De Spiegelaere W, Dern-Wieloch J, Weigel R, Schumacher V, Schorle H, Nettersheim D, Bergmann M, Brehm R, Kliesch S, Vandekerckhove L, Fink, C. 2015. Reference gene validation for RT-qPCR, a note on different available software packages. PLoS ONE 10(3): e0122515 DOI 10.1371/journal.pone.0122515.

Dheda K, Huggett J, Bustin S, Johnson M, Rook G, Zumla A. 2004. Validation of housekeeping genes for normalizing RNA expression in real-time PCR. Biotechniques 37:112-114.

Doi K, Matsuura M, Kawara A, Baba S. 1979. Treatment of diabetes with glucomannan (konjac mannan). The Lancet 313(8123): 987-988.

Fang W, Wu P. 2004. Variations of konjac glucomannan (KGM) from Amorphophallus konjac and its refined powder in China. Food Hydrocolloids 18(1): 167-170 DOI 10.1016/S0268-005X(03)00044-4.

Fan J, Wang K, Liu M, He Z. 2008. In vitro evaluations of konjac glucomannan and xanthan gum mixture as the sustained release material of matrix tablet. Carbohydrate Polymers 73(2): 241-247 DOI 10.1016/j.carbpol.2007.11.027.

Farvid MS, Eliassen AH, Cho E, Liao X, Chen W-Y, Willett W-C. 2016. Dietary fiber intake in young adults and breast cancer risk. Pediatrics 137(3): 1-11 DOI 10.1542/peds.2015-1226.

Gille S, Cheng K, Skinner ME, Liepman AH, Wilkerson CG, Pauly M. 2001. Deep sequencing of voodoo lily (Amorphophallus konjac): an approach to identify relevant genes involved in the synthesis of the hemicellulose glucomannan. Planta 234(3): 515-526 DOI 10.1007/s00425-011-1422-z.

Gimeno J, Eattock N, Van Deynze A, Blumwald E. 2014. Selection and Validation of Reference Genes for Gene Expression Analysis in Switchgrass (Panicum virgatum) Using Quantitative Real-Time RT-PCR. PLoS ONE 9(3): e91474-e91474 DOI 10.1371/journal.pone.0091474.

Gopaulchan D, Lennon A M, Umaharan P. 2013. Identification of reference genes for expression studies using quantitative RTPCR in spathe tissue of Anthurium andraeanum (Hort.). Scientia Horticulturae 153: 1-7 DOI 10.1016/j.scienta.2013.01.024.

Gu C, Chen S, Liu Z, Shan H, Luo H, Guan Z, Chen F. 2011. Reference gene selection for quantitative real-time PCR in Chrysanthemum subjected to biotic and abiotic stress. Molecular Biotechnology 49:192-197 DOI 10.1007/s12033-011-9394-6. 
436

437

438

439

440

441

442

443

444

445

446

447

448

449

450

451

452

453

454

455

456

457

458

459

460

461

462

463

464

465

466

467

468

469

470

471

472

473

474

475

Hellemans J, Mortier G, De Paepe A, Speleman F, Vandesompele J. 2007. qBase relative quantification framework and software for management and automated analysis of real-time quantitative pcr data. Genome Biology 8(2): R19 DOI: 10.1186/gb-2007-8-2-r19.

Hellemans J, Vandesompele J. 2014. Selection of reliable reference genes for RT-qPCR analysis. Methods in Molecular Biology 1160(1160): 19-26 DOI 10.1007/978-1-4939-0733-5_3.

Hisbergues M, Christiansen G, Rouhiainen L, Sivonen K, Börner T. 2014. PCR-based identification of microcystin-producing genotypes of different cyanobacterial species. Archives of Microbiology 180(6): 402-410 DOI 10.1007/s00203-003-0605-9.

Huang G, Gong S, Xu W, Li P, Zhang D, Qin L, Li W, Li X. 2011. GhHyPRP4, a cotton gene encoding putative hybrid prolinerich protein, is preferentially expressed in leaves and involved in plant response to cold stress. Acta Biochimica Et Biophysica Sinica 43(7):519-527 DOI 10.1093/abbs/gmr040.

Huang L, Yan H, Jiang X, Zhang X, Zhang Y, Huang X, Zhang Y, Miao J, Xu B, Frazier T, Zhao B. 2014. Evaluation of candidate reference genes for normalization of quantitative RT-PCR in switchgrass under various abiotic stress conditions. BioEnergy Research 7(4): 1201-1211 DOI 10.1007/s12155-014-9457-1.

Huggett J, Dheda K, Bustin S, Zumla A. 2005. Real-time RT-PCR normalisation; strategies and considerations. Genes and immunity 6(4): 279-284 DOI 10.1038/sj.gene.6364190.

Itoh J, Sato Y, Hibara K, Shimizu-Sato S, Kobayashi H, Takehisa H, Sanguinet KA, Namiki N, Nagamura Y. 2016. Genomewide analysis of spatiotemporal gene expression patterns during early embryogenesis in rice. Development 143(7): 1217-1227 DOI $10.1242 /$ dev.123661.

Jakob U, Gaestel M, Engel K, Buchner J.1993. Small heat shock proteins are molecular chaperones. Journal of Biological Chemistry 268(3): 1517-1520.

Jiang Q, Wang F, Li M-Y, Ma J, Tan G-F, Xiong A-S. 2014. Selection of suitable reference genes for qPCR normalization under abiotic stresses in Oenanthe javanica (BI.) DC. PLoS ONE 9(3): e92262

DOI 10.1371/journal.pone.0092262.

Kaats GR, Bagchi D, Preuss HG. 2015. Konjac glucomannan dietary supplementation causes significant fat loss in compliant overweight adults. Journal of the American College of Nutrition 2015:1-7

DOI 10.1080/07315724.2015.1009194.

Kong Q, Yuan J, Gao L, Zhao S, Jiang W, Huang Y, Bie Z. 2014. Identification of suitable reference genes for gene expression normalization in qRT-PCR analysis in watermelon. PLoS ONE 9(2): e90612

DOI 10.1371/journal.pone.0090612.

Kumar K, Muthamilarasan M, Prasad M. 2013. Reference genes for quantitative real-time PCR analysis in the model plant foxtail millet (Setaria, italica, L.) subjected to abiotic stress conditions. Plant Cell Tissue \& Organ Culture 115(1):13-22 DOI 10.1007/s11240-013-0335-X.

Lee PD, Sladek R, Greenwood CM, Hudson TJ. 2002. Control genes and variability: absence of ubiquitous reference transcripts in diverse mammalian expression studies. Genome Research 12(2): 292-297

DOI 10.1101/gr.217802.

Li L, Xu J, Xu Z H, Xue HW. 2005. Brassinosteroids stimulate plant tropisms through modulation of polar auxin transport in Brassica and Arabidopsis. The Plant Cell 17(10): 2738-2753 DOI 10.1105/tpc.105.034397.

Lin Y, Zhang C, Lan H, Gao S, Liu H, Liu J, Cao M, Pan G, Rong T, Zhang S. 2014. Validation of potential reference genes for qPCR in maize across abiotic stresses, hormone treatments, and tissue types. PLoS ONE 9(5): e95445 DOI 10.1371/journal.pone.0095445. 
Liu D, Shi L, Han C, Yu J, Li D, Zhang Y. 2012. Validation of reference genes for gene expression studies in virus-infected Nicotiana benthamiana using quantitative real-time PCR. PLoS ONE 7(9): e46451 DOI 10.1371/journal.pone.0046451.

Løvdal T, Lillo C.2009. Reference gene selection for quantitative real-time PCR normalization in tomato subjected to nitrogen, cold, and light stress. Analytical biochemistry 387(2): 238-242 DOI 10.1016/j.ab.2009.01.024.

Maksup S, Supaibulwatana K, Selvaraj G. 2013. High-quality reference genes for quantifying the transcriptional responses of Oryza sativa L. (ssp. indica and japonica) to abiotic stress conditions. Chinese Science Bulletin 58(16): 1919-1930 DOI 10.1007/s11434-013-5726-1.

Martins PK, Mafra V, de Souza WR, Ribeiro AP, Vinecky F, Basso MF, da Cunha BA, Kobayashi AK, Molinari HB. 2016. Selection of reliable reference genes for RT-qPCR analysis during developmental stages and abiotic stress in Setaria viridis. Scientific Reports 6 DOI 10.1038/srep28348.

Nolan T, Hands RE, Bustin SA. 2006. Quantification of mRNA using real-time RT-PCR. Nature protocols 1(3): 1559-1582 DOI 10.1038/nprot.2006.236.

Paolacci AR, Tanzarella OA, Porceddu E, Ciaffi M. 2009. Identification and validation of reference genes for quantitative RTPCR normalization in wheat. BMC molecular biology 10(1): 1 DOI 10.1186/1471-2199-10-11.

Pfaffl MW. 2001. A new mathematical model for relative quantification in real-time RT-PCR. Nucleic Acids Research 29(9): e45 DOI 10.1093/nar/29.9.e45.

Pfaffl MW. 2005. Quantification strategies in real time PCR. AZ of quantitative PCR. Edited by: Bustin SA. 2004 La Jolla. CA: International University Line: 1-20.

Pfaffl MW, Tichopad A, Prgomet C, Neuvians TP. 2004. Determination of stable housekeeping genes, differentially regulated target genes and sample integrity: BestKeeper-Excel-based tool using pair-wise correlations. Biotechnology letters 26(6): 509-515 DOI 10.1023/B:BILE.0000019559.84305.47.

Prosky L, Asp NG, Schweizer TF, DeVries JW, Furda I. 1987. Determination of insoluble, soluble, and total dietary fiber in foods and food products: interlaboratory study. Journal-Association of Official Analytical Chemists 71(5): 1017-1023.

Qi S, Yang L, Wen X, Hong Y, Song X, Zhang M, Dai S. 2016. Reference gene selection for RT-qPCR analysis of flower development in Chrysanthemum morifolium and Chrysanthemum lavandulifolium. Frontiers in plant science 7 DOI 10.3389/fpls.2016.00287.

Reddy PS, Reddy DS, Sharma KK, Bhatnagar-Mathur P, Vadez V. 2015. Cloning and validation of reference genes for normalization of gene expression studies in pearl millet [Pennisetum glaucum (L.) R. Br.] by quantitative real-time PCR. Plant Gene 1: 35-42 DOI 10.1016/j.plgene.2015.02.001.

Saha P, Blumwald E. 2014. Assessing reference genes for accurate transcript normalization using quantitative real-time PCR in pearl millet [Pennisetum glaucum (L.) R. Br.]. PLoS ONE 9(8): e106308 DOI 10.1371/journal.pone.0106308.

Schneeman BO. 1986. Dietary fiber: physical and chemical properties, methods of analysis, and physiological effects. Food technology.

Sonenberg N, Dever TE. 2003. Eukaryotic translation initiation factors and regulators. Current opinion in structural biology 13(1): 56-63.

Sun W, Van Montagu M, Verbruggen N. 2002. Small heat shock proteins and stress tolerance in plants. Biochimica et Biophysica Acta (BBA)-Gene Structure and Expression 1577(1): 1-9.

Thellin O, Zorzi W, Lakaye B, De Borman B, Coumans B, Hennen G, Grisar T, Igout A, Heinen E. 1999. Housekeeping 
517

518

519

520

521

522

523

524

525

526

527

528

529

530

531

532

533

534

535

536

537

538

539

540

541

542

543

544

545

546

547

548

549

550

genes as internal standards: use and limits. Journal of biotechnology 75(2): 291-295.

Thompson D, Regev A, Roy S. 2015. Comparative analysis of gene regulatory networks: from network reconstruction to evolution. Annual review of cell and developmental biology 31: 399-428

DOI 10.1146/annurev-cellbio-100913-012908.

Untergasser A, Nijveen H, Rao X, Bisseling T, Geurts R, Leunissen JA. 2007. Primer3Plus, an enhanced web interface to Primer3. Nucleic Acids Research 35(suppl_2):71-4 DOI 10.1093/nar/gkm306.

Vandesompele J, De Preter K, Pattyn F, Poppe B, Van Roy N, De Paepe A, Speleman F. 2002. Accurate normalization of realtime quantitative RT-PCR data by geometric averaging of multiple internal control genes. Genome Biology 3(7):1-12 DOI 10.1186/gb-2002-3-7-research0034.

Vermeulen J, De Preter K, Lefever S, Nuytens J, De Vloed F, Derveaux S, Hellemans J, Speleman F, Vandesompele J. 2011. Measurable impact of RNA quality on gene expression results from quantitative PCR. Nucleic acids research 39(9): e63-e63 DOI 10.1093/nar/gkr065.

Wang M, Wang Q, Zhang B. 2013. Evaluation and selection of reliable reference genes for gene expression under abiotic stress in cotton (Gossypium hirsutum L.). Gene 530(1): 44-50 DOI 10.1016/j.gene.2013.07.084.

Wan H, Zhao Z, Qian C, Sui Y, Malik AA, Chen J. 2010. Selection of appropriate reference genes for gene expression studies by quantitative real-time polymerase chain reaction in cucumber. Analytical biochemistry 399(2): $257-261$ DOI 10.1016/j.ab.2009.12.008.

Wu WT, Chen HL. 2011. Effects of konjac glucomannan on putative risk factors for colon carcinogenesis in rats fed a high-fat diet. Journal of agricultural and food chemistry 59(3): 989-994 DOI 10.1021/jf103532x.

Xia W, Mason AS, Xiao Y, Liu Z, Yang Y, Lei X, Wu X, Ma Z, Peng M. 2014. Analysis of multiple transcriptomes of the African oil palm (Elaeis guineensis) to identify reference genes for RT-qPCR. Journal of biotechnology 184: 63-73 DOI 10.1016/j.jbiotec.2014.05.008.

Yang H, Liu J, Huang S, Guo T, Deng L, Hua W. 2014. Selection and evaluation of novel reference genes for quantitative reverse transcription PCR (qRT-PCR) based on genome and transcriptome data in Brassica napus L. Gene 538(1): 113-122 DOI 10.1016/j.gene.2013.12.057.

Zhang Y, Xie B, Gan X. 2005. Advance in the applications of konjac glucomannan and its derivatives. Carbohydrate Polymers 60(1): 27-31 DOI 10.1016/j.carbpol.2004.11.003.

Zheng X, Pan C, Diao Y, You Y, Yang C, Hu Z. 2013. Development of microsatellite markers by transcriptome sequencing in two species of Amorphophallus (Araceae). BMC genomics 14(1): 1

DOI 10.1186/1471-2164-14-490.

Zmienko A, Samelak-Czajka A, Goralski M, Sobieszczuk-Nowicka E, Kozlowski P, Figlerowicz M. 2015. Selection of reference genes for qPCR-and ddPCR-based analyses of gene expression in senescing barley leaves. PLoS ONE 10(2): e0118226 DOI 10.1371/journal.pone.0118226. 


\section{Table 1 (on next page)}

8 candidate reference genes' accession numbers of 4 monocots in GenBank. 


\begin{tabular}{ccccl}
\hline Name & Anthurium andraeanum & Elaeis guineensis & Phoenix dactylifera & Musa acuminata \\
\hline$E F 1-a$ & JN602204.1 & XM_010939210.2 & XM_008792592.1 & XM_009404789.2 \\
$T U B$ & JN602205.1 & XM_010907949.2 & XM_008789128.2 & XM_009404284.2 \\
ACTB & JN602202.1 & XM_010932692.2 & XM_008783179.2 & XM_009392480.2 \\
H3 & No find & XM_019852580.1 & XM_008813893.2 & XM_009414503.2 \\
CYP & JN602201.1 & XM_010942984.2 & XM_008801198.2 & XM_009414618.2 \\
GAPDH & JN602203.1 & XM_010912103.1 & XM_008802722.2 & XM_009389227.2 \\
EIF4A & JN602200.1 & XM_010927143.2 & XM_008799912.2 & XM_009417246.2 \\
UBQ & JN602199.1 & XM_019854937.1 & XM_008811850.2 & XM_009393249.2 \\
\hline
\end{tabular}

1 
Table 2 (on next page)

Degenerate primers used to clone 8 candidate reference genes for RT-qPCR in Amorphophallus. 


\begin{tabular}{ccc}
\hline Candidate reference genes & Forward primer sequence [5'-3'] & Reverse primer sequence [5'-3'] \\
\hline$E F 1-a$ & GACTGCCACACCTSMCAYA & CKACRCTCTTGATRACACCR \\
$T U B$ & CGCCCYGACAACTTCGTCTT & CTTGGMRTCCCACATCTGCTG \\
$A C T B$ & AYGACATGGAGAARATYTGGC & CACCAGARTCMARCACAATAC \\
$H 3$ & SGTSAAGAAGCCCCACC & RCGRGCAAGCTGGATGT \\
$C Y P$ & GAGAACTTCMGGGCNCTC & AYCTGSCCGAACACGACG \\
$G A P D H$ & CAADGACAAGGCTGCDGCTCA & CTTKGCDGCACCAGTGCTGC \\
$E I F 4 A$ & GATGAGCTNACCCTTGAGGGT & GCTGDACATCAATACCACGAGC \\
$U B Q$ & TRACGGGBAAGACCATCACN & ACCTTGTARAACTGGAGGASDGCG \\
\hline
\end{tabular}

1 


\section{Table 3(on next page)}

Description of Amorphophallus candidate reference genes for RT-qPCR.

"Source" represents which species these genes of different accession number belong to. 


\begin{tabular}{|c|c|c|c|c|c|}
\hline Name & Description & Accession number & Source & Length（bp） & Identity $(\%)$ \\
\hline$E F 1-a$ & Elongation factor $1-\alpha$ & XM_015774249.1 & Oryza sativa & 241 & 87 \\
\hline$T U B$ & $\beta$-tubulin & L33263.1 & Oryza sativa & 636 & 85 \\
\hline$A C T B$ & $\beta$-actin & XM_015784227 & Oryza sativa & 231 & 83 \\
\hline$H 3$ & Histone $\mathrm{H} 3.2$ & XM_015784228.1 & Oryza sativa & 283 & 90 \\
\hline$C Y P$ & Cyclophilin & XM_008680450.1 & Zea mays & 317 & 86 \\
\hline GAPDH & Glyceraldehyde-3-phosphate dehydrogenase & XM_015780140.1 & Oryza sativa & 334 & 86 \\
\hline$E I F 4 A$ & Eukaryotic initiation factor $4 \mathrm{~A}$ & NM_001111926.1 & Zea mays & 304 & 87 \\
\hline$U B Q$ & Ubiquitin & NM_001138130.1 & Zea mays & 301 & 94 \\
\hline
\end{tabular}

1 


\section{Table 4(on next page)}

Description of 9 candidate reference genes and SHSP gene in Amorphophallus.

Tm represents melt temperature and was calculated by the Bio-Rad CFX96 Real-Time PCR system. 


\begin{tabular}{ccccccc}
\hline Name & Forward primer sequence $\left[{ }^{\prime}{ }^{\prime}-3^{\prime}\right]$ & Reverse primer sequence $\left[5^{\prime}-3^{\prime}\right]$ & Amplicon length $(\mathrm{bp})$ & $T m\left({ }^{\circ} \mathrm{C}\right)$ & $E(\%)$ & $R^{2}$ \\
\hline$R P$ & GGACGAAGAGCAATGACCC & ACCCTTTCCCCGAACCCA & 118 & 79.5 & 92.8 & 0.991 \\
$E F 1-a$ & AAGTTCCTGAAGAATGGCGAT & GTCCCTCACGGCAAACCTACC & 111 & 82.5 & 99.8 & 0.990 \\
$T U B$ & GCTGGTTGAGAATGCCGATGAA & GCAGAAATAAGGTGATTGAGAT & 120 & 80 & 97.7 & 0.998 \\
$A C T B$ & CCAACAGAGAGAAGATGACA & ACCAGAATCCAGCACAATAC & 128 & 79 & 94.3 & 0.999 \\
$H 3$ & CGGGAGATCGCTCAGGACT & CATGATGGTGACGCGCTTG & 139 & 86.5 & 96.8 & 0.990 \\
$C Y P$ & CAAGCCCCTCCACTACAAGG & CCGGTGTGCTTCTTCACGAA & 153 & 86 & 93.0 & 0.991 \\
GAPDH & ACTAACTGCCTCGCTCCTC & CAGCCCTTCCACCCCTCCA & 145 & 82 & 93.3 & 0.990 \\
$E I F 4 A$ & ACAAGATGAGGAGCAGGG & GGTGATAAGGACACGAGA & 116 & 79.5 & 109.5 & 0.990 \\
$U B Q$ & GGACACCATCGACAACGTGA & TTCTTCTTGCGCTTCTTGGC & 189 & 87.5 & 107.7 & 0.997 \\
$S H S P$ & ATCAAGGTCCAGGTGGAGGA & GGCAGCGAGAACTTCCTCAT & 131 & 88 & 96.1 & 0.996 \\
\hline
\end{tabular}

1 


\section{Table 5 (on next page)}

Expression stability values for 9 candidate genes calculated using geNorm.

Aa represents $A$. albus, and $A$ k represents $A$. konjac. Total set contains all test samples. 


\begin{tabular}{|c|c|c|c|c|c|c|c|}
\hline Rank & Heat in $A a$ & Heat in $A k$ & Waterlogging in $A a$ & Waterlogging in $A k$ & Tissues in $A a$ & Tissues in $A k$ & Total \\
\hline 1 & $E F 1-a(1.07)$ & $H 3(0.78)$ & $E F 1-a(0.66)$ & $E F 1-a(1.27)$ & $U B Q(1.33)$ & $\operatorname{EIF} 4 A(1.43)$ & EIF4A (1.24) \\
\hline 2 & EIF4A (1.12) & $E I F 4 A(0.82)$ & EIF4A (0.71) & EIF4A (1.31) & $E F 1-a(1.49)$ & $E F 1-a(1.50)$ & $E F 1-a(1.28)$ \\
\hline 3 & $U B Q(1.16)$ & $E F 1-a(0.83)$ & $T U B(0.72)$ & $T U B(1.44)$ & $\operatorname{EIF} 4 A(1.50)$ & $C Y P(1.53)$ & $U B Q(1.42)$ \\
\hline 4 & GAPDH (1.19) & $U B Q(0.89)$ & $R P(0.74)$ & $U B Q(1.49)$ & $C Y P(1.50)$ & $R P(1.79)$ & $H 3(1.42)$ \\
\hline 5 & $A C T B(1.26)$ & $A C T B(0.90)$ & $H 3(0.74)$ & $R P(1.50)$ & $H 3(1.64)$ & $A C T B(1.79)$ & $A C T B(1.52)$ \\
\hline 6 & $H 3(1.28)$ & $T U B(1.07)$ & $A C T B(0.98)$ & $A C T B(1.57)$ & $R P(1.64)$ & $U B Q(1.99)$ & CYP (1.59) \\
\hline 7 & CYP (1.35) & $C Y P(1.10)$ & CYP (1.05) & $H 3(1.62)$ & $T U B(2.01)$ & $T U B(2.01)$ & $R P(1.59)$ \\
\hline 8 & $T U B(1.84)$ & GAPDH (1.17) & $U B Q(1.14)$ & GADPH (1.74) & $A C T B(2.11)$ & $H 3(2.11)$ & $T U B(1.60)$ \\
\hline 9 & $R P(1.90)$ & $R P(1.32)$ & GAPDH (1.45) & CYP (1.75) & GADPH (3.25) & GAPDH (2.35) & GAPDH (1.93) \\
\hline
\end{tabular}

1 


\section{Table 6(on next page)}

Expression stability values for 9 candidate genes calculated using NormFinder.

Aa represents $A$. albus, and $A k$ represents $A$. konjac. Total set contains all test samples. 


\begin{tabular}{|c|c|c|c|c|c|c|c|}
\hline Rank & Heat in $A a$ & Heat in $A k$ & Waterlogging in $A a$ & Waterlogging in $A k$ & Tissues in $A a$ & Tissues in $A k$ & Total \\
\hline 1 & $E F 1-a(0.32)$ & $H 3(0.20)$ & EIF4A (0.09) & $E F 1-a(0.43)$ & $U B Q(0.28)$ & EIF4A (0.41) & EIF4A (0.39) \\
\hline 2 & EIF4A (0.37) & EIF4A (0.27) & $E F 1-a(0.18)$ & EIF4A (0.49) & $R P(0.57)$ & $E F 1-a(0.55)$ & $E F 1-a(0.47)$ \\
\hline 3 & $U B Q(0.44)$ & $E F 1-a(0.28)$ & $T U B(0.18)$ & $T U B(0.65)$ & EIF4A $(0.60)$ & $C Y P(0.56)$ & $U B Q(0.63)$ \\
\hline 4 & $G A P D H(0.46)$ & $A C T B(0.37)$ & $H 3(0.25)$ & $U B Q(0.72)$ & $E F 1-a(0.62)$ & $R P(0.84)$ & $H 3(0.63)$ \\
\hline 5 & $A C T B(0.55)$ & $U B Q(0.38)$ & $R P(0.25)$ & $R P(0.73)$ & $H 3(0.71)$ & $A C T B(0.87)$ & $A C T B(0.75)$ \\
\hline 6 & $H 3(0.59)$ & $T U B(0.57)$ & $A C T B(0.53)$ & $A C T B(0.80)$ & $C Y P(0.74)$ & $U B Q(1.04)$ & $T U B(0.83)$ \\
\hline 7 & $C Y P(0.67)$ & CYP (0.59) & $C Y P(0.57)$ & $H 3(0.87)$ & $T U B(1.03)$ & $T U B(1.14)$ & $R P(0.83)$ \\
\hline 8 & $R P(1.12)$ & GAPDH $(0.69)$ & $U B Q(0.66)$ & GAPDH $(0.96)$ & $A C T B(1.21)$ & H3 (1.19) & $C Y P(0.83)$ \\
\hline 9 & $T U B(1.16)$ & $R P(0.81)$ & GAPDH $(0.93)$ & CYP (0.98) & GAPDH (2.14) & $G A D P H(1.41)$ & GAPDH (1.15) \\
\hline
\end{tabular}

1 


\section{Table 7 (on next page)}

Expression stability values for 9 candidate genes calculated using BestKeeper.

Aa represents $A$. albus, and $A k$ represents $A$. konjac. Total set contains all test samples. 


\begin{tabular}{cccccccc}
\hline Rank & Heat in $A a$ & Heat in $A k$ & Waterlogging in $A a$ & Waterlogging in $A k$ & Tissues in $A a$ & Tissues in $A k$ & Total \\
\hline \multirow{2}{*}{1} & $E I F 4 A$ & $E I F 4 A$ & $E I F 4 A$ & $T U B$ & $C Y P$ & $C Y P$ & $H 3$ \\
& $(1.49 \pm 0.46)$ & $(1.66 \pm 0.40)$ & $(1.12 \pm 0.38)$ & $(1.29 \pm 1.09)$ & $(1.17 \pm 0.96)$ & $(1.26 \pm 0.36)$ & $(1.65 \pm 1.50)$ \\
2 & $A C T B$ & $E F 1-a$ & $R P$ & $R P$ & $E F 1-\alpha$ & $E F 1-\alpha$ & $T U B$ \\
& $(1.58 \pm 0.84)$ & $(1.83 \pm 0.34)$ & $(1.21 \pm 0.37)$ & $(1.80 \pm 2.96)$ & $(1.39 \pm 0.67)$ & $(1.31 \pm 0.89)$ & $(1.79 \pm 0.61)$ \\
3 & $E F 1-\alpha$ & $H 3$ & $A C T B$ & $A C T B$ & $E I F 4 A$ & $E I F 4 A$ & $U B Q$ \\
& $(1.62 \pm 0.47)$ & $(1.83 \pm 0.30)$ & $(1.25 \pm 0.84)$ & $(1.84 \pm 2.55)$ & $(1.59 \pm 0.58)$ & $(1.40 \pm 1.08)$ & $(1.81 \pm 0.31)$ \\
4 & $H 3$ & $A C T B$ & $H 3$ & $C Y P$ & $R P$ & $H 3$ & $E I F 4 A$ \\
& $(1.69 \pm 0.78)$ & $(1.89 \pm 0.49)$ & $(1.47 \pm 037)$ & $(1.91 \pm 1.88)$ & $(1.62 \pm 1.76)$ & $(1.65 \pm 1.24)$ & $(1.93 \pm 0.63)$ \\
5 & $U B Q$ & $G A D P H$ & $T U B$ & $U B Q$ & $U B Q$ & $R P$ & $E F 1-\alpha$ \\
& $(1.94 \pm 0.60)$ & $(1.97 \pm 0.99)$ & $(1.86 \pm 0.34)$ & $(1.95 \pm 0.75)$ & $(1.92 \pm 0.98)$ & $(2.15 \pm 1.27)$ & $(1.97 \pm 0.61)$ \\
6 & $R P$ & $C Y P$ & $E F 1-a$ & $H 3$ & $A C T B$ & $G A P D H$ & $C Y P$ \\
& $(1.98 \pm 1.36)$ & $(2.11 \pm 0.83)$ & $(1.97 \pm 0.34)$ & $(2.11 \pm 1.35)$ & $(2.07 \pm 1.55)$ & $(2.19 \pm 1.88)$ & $(2.06 \pm 0.75)$ \\
7 & $G A P D H$ & $U B Q$ & $U B Q$ & $G A D P H$ & $H 3$ & $T U B$ & $R P$ \\
& $(2.04 \pm 0.61)$ & $(2.11 \pm 0.49)$ & $(3.12 \pm 0.95)$ & $(2.24 \pm 1.77)$ & $(2.13 \pm 0.91)$ & $(2.89 \pm 1.20)$ & $(2.08 \pm 0.76)$ \\
& $C Y P$ & $R P$ & $C Y P$ & $E F 1-\alpha$ & $T U B$ & $U B Q$ & $G A D P H$ \\
& $(2.94 \pm 0.67)$ & $(2.17 \pm 1.14)$ & $(3.52 \pm 0.59)$ & $(2.63 \pm 0.67)$ & $(2.47 \pm 1.45)$ & $(2.90 \pm 1.39)$ & $(2.32 \pm 0.33)$ \\
& $T U B$ & $T U B$ & $G A D P H$ & $E I F 4 A$ & $G A P D H$ & $A C T B$ & $A C T B$ \\
& $(4.03 \pm 1.20)$ & $(2.61 \pm 0.61)$ & $(6.47 \pm 1.04)$ & $(2.64 \pm 0.75)$ & $(6.90 \pm 2.45)$ & $(3.39 \pm 1.22)$ & $(2.51 \pm 0.51)$ \\
\hline
\end{tabular}

1 


\section{Figure 1 (on next page)}

Thres hold cycle values (Cq) of 9candidate genes across 78 CDNA samples in RT-qPCR.

The lower and upper ends of each box represent the $1 / 4$ and 3/4 quartiles. Whiskers

represent the maximum and minimum Cq values. The median Cq values are depicted by the dots in the boxes. 


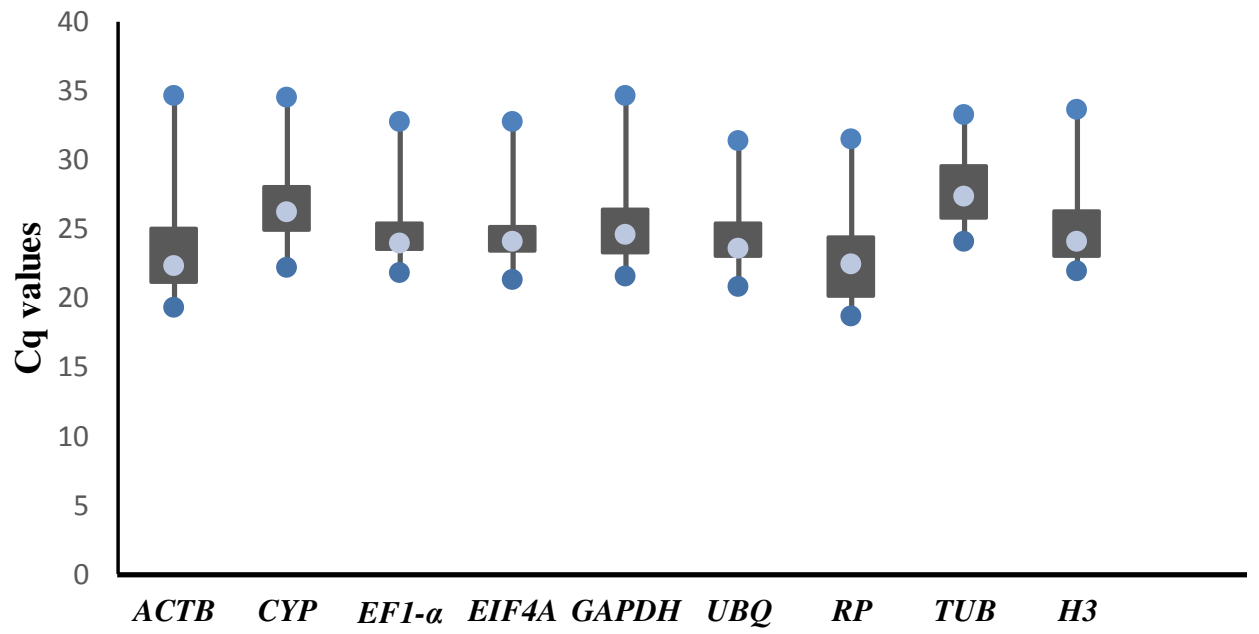




\section{Figure 2 (on next page)}

Gene expression stability(M) and ranking of potential reference genes within different treatment groups as calculated by geNorm.

The ordinate value represents the average expression stability value (M) and the abscissas show the 9 candidate reference genes. A lower $M$ value represents more stable expression as analyzed by geNorm algorithm in different sets, including heat stress in $A$. albus (A), heat stress in $A$. konjac (B), waterlogging in $A$. albus (C), waterlogging in $A$. konjac (D), different tissues in $A$. albus (E), different tissues in $A$. konjac (F), and total $(\mathrm{G})$. The total set contains all test samples. 
A

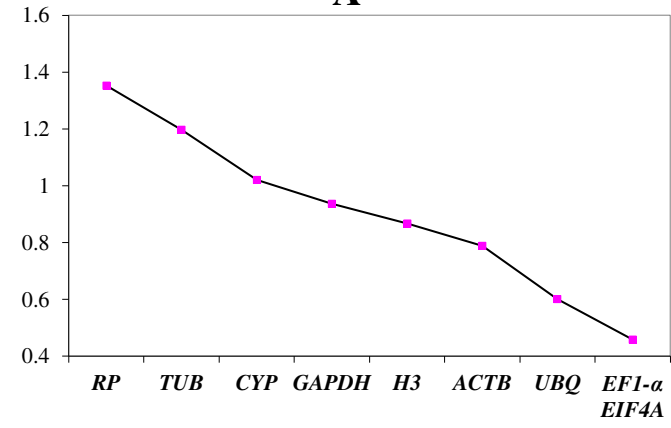

C

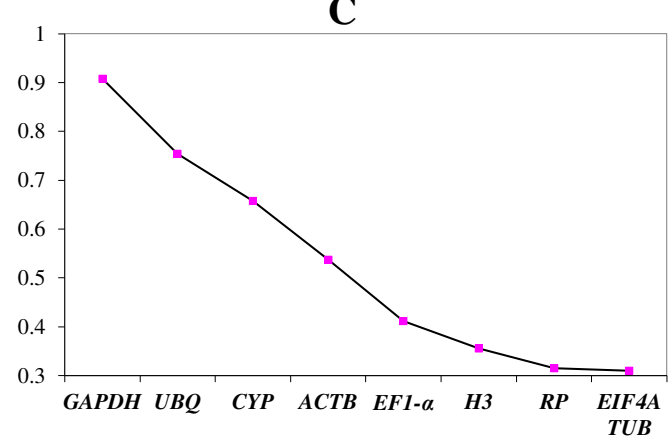

$\mathbf{E}$

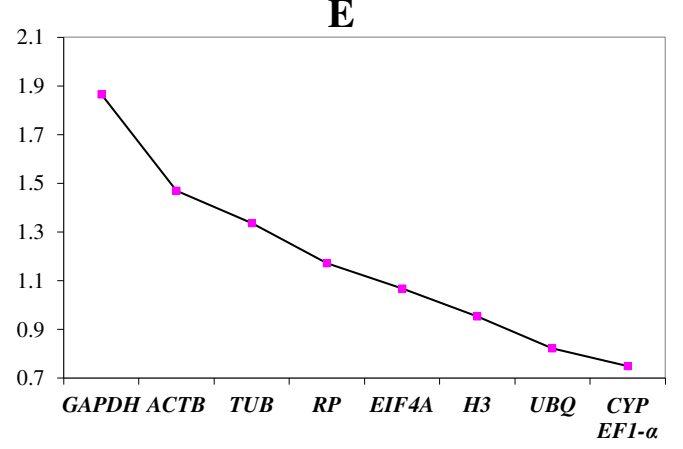

B

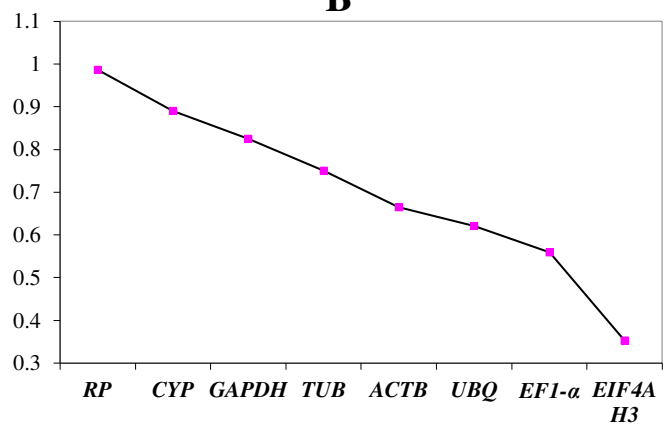

D

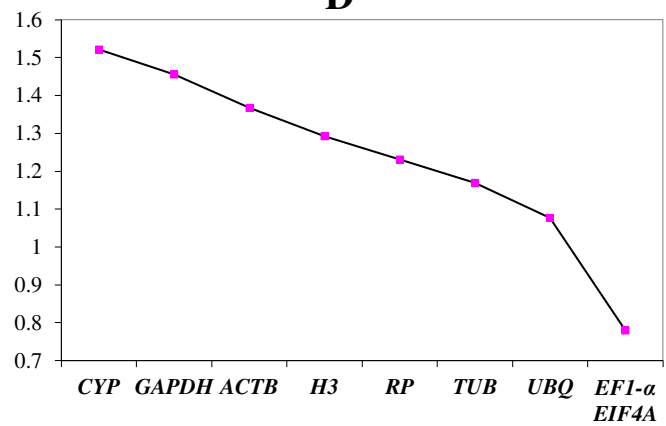

F

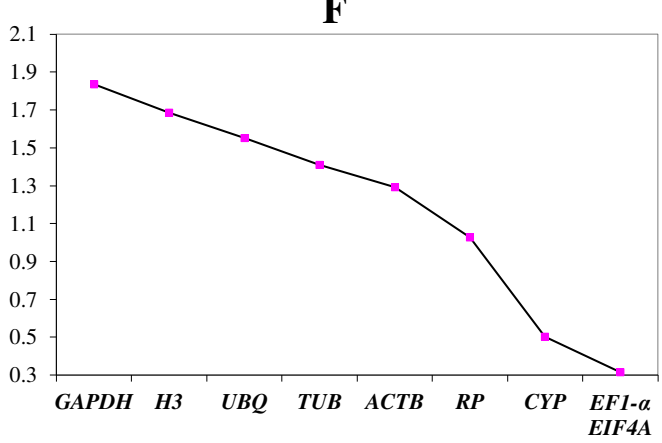

G

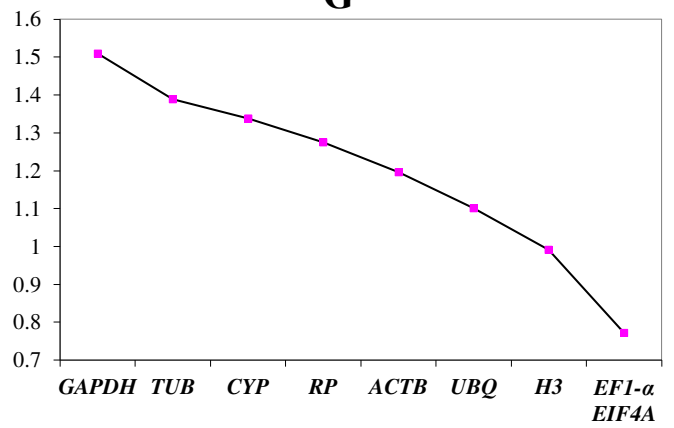

$<::::$ Least stable genes

Most stable genes ::::>> 


\section{Figure 3 (on next page)}

Gene expression stability $(M)$ and ranking of potential reference genes within different treatment groupsas calculated by geNorm when EIF4A was excluded.

The ordinate value represents the average expression stability value (M) and the abscissas show the 9 candidate reference genes. A lower $M$ value represents more stable expression as analyzed by geNorm algorithm in different sets, including heat stress in $A$. albus (A), heat stress in A. konjac (B), waterlogging in A. albus (C), waterlogging in A. konjac (D), different tissues in $A$. albus (E), different tissues in $A$. konjac (F), and total (G). The total set contains all test samples. 
A

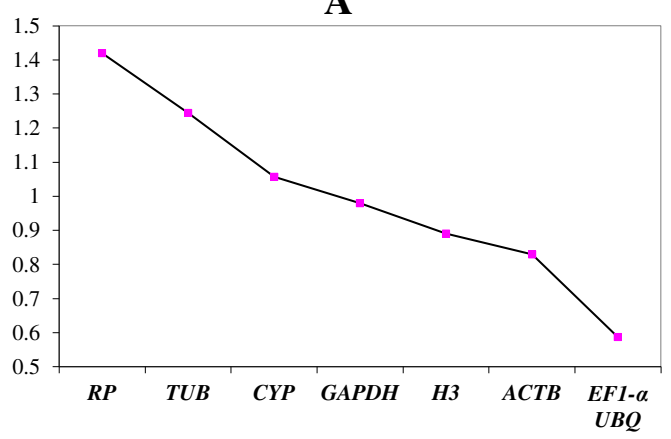

C

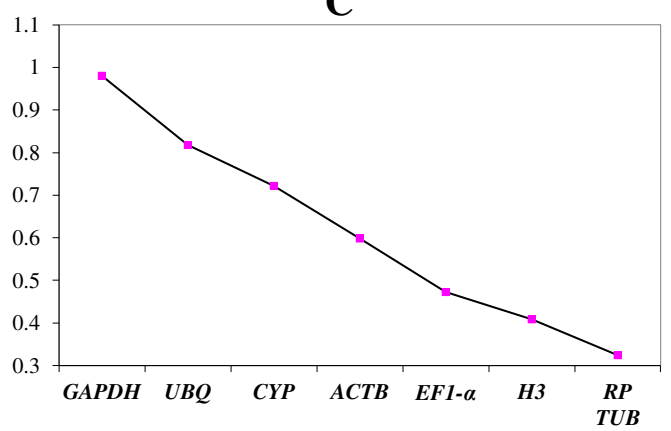

E

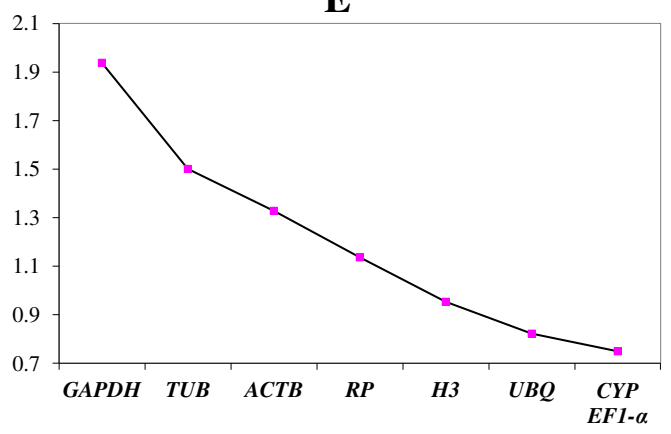

B

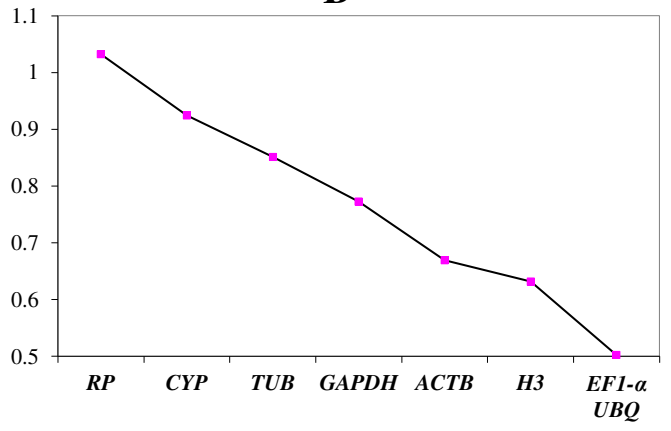

D

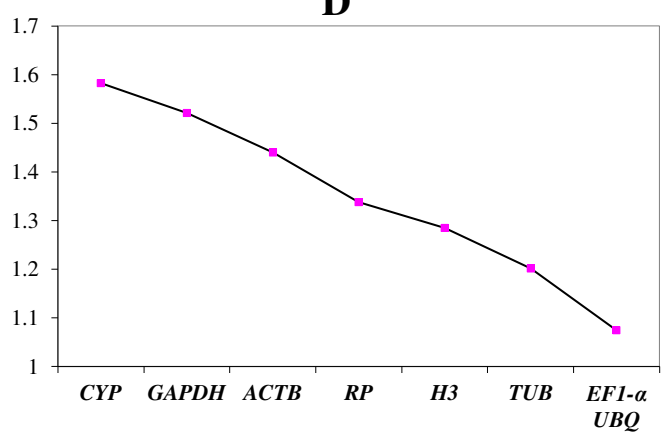

F

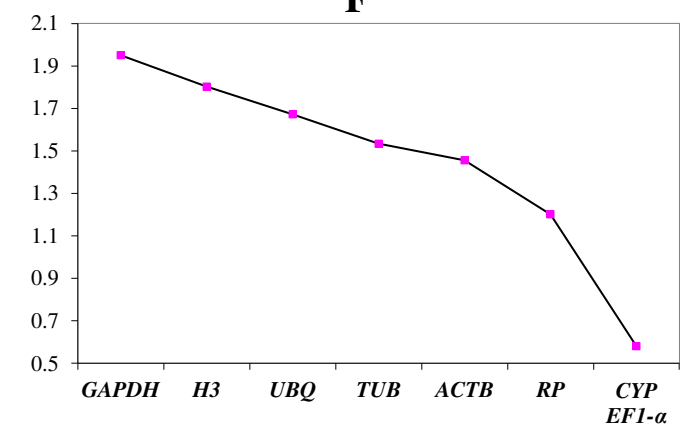

G

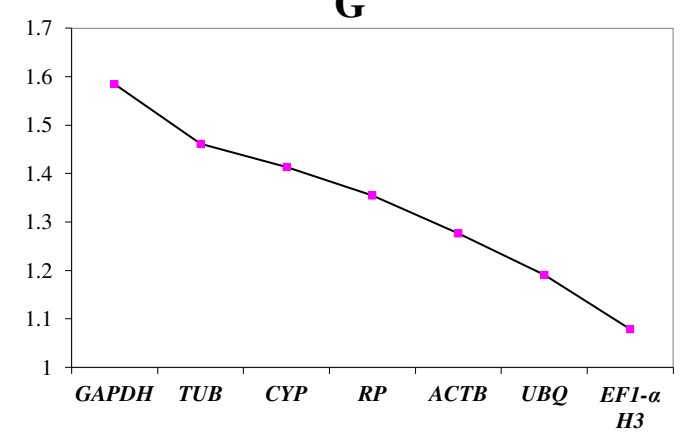

<::::: Least stable genes

Most stable genes :::::> 


\section{Figure 4(on next page)}

Determination of the optimal number of reference genes for normalization by pairwise variation determined by geNorm.

Aa represented $A$. albus, and $A k$ represented $A$. konjac. Total set contains all test samples. 


\begin{tabular}{l|l}
\multicolumn{7}{|c|}{ PairWise Variation } \\
\hline
\end{tabular}


Figure $\mathbf{5}$ (on next page)

Relative quantification of SHSP gene in leaves atdifferent time points after heat treatment in A.albus and A. konjac.

A shows the relative expression of SHSP in A. albus and B represents the expression level of SHSP in A. konjac. We selected the validated best reference gene(s) under heat stress and two traditional reference genes (ACTB and GADPH) as normalization factors. Asterisks (*) indicate significant differences $(P<0.05)$ and $P$ value was calculated by student's $T$ test. Sum of squares of deviations were calculated based on the average expression level normalized by 7 identified normalization factors. 
A

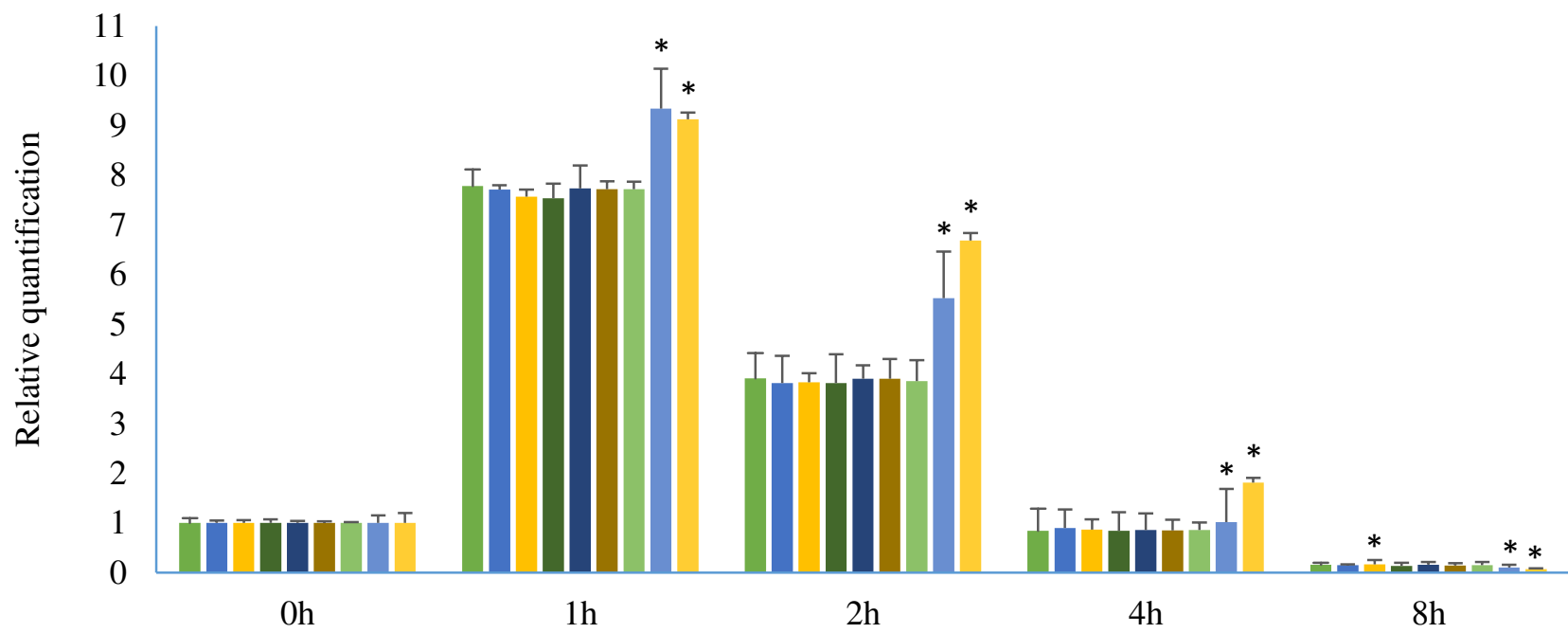

$\square E F 1-a \square E I F 4 A \square H 3 \backsim U B Q \square E F 1-a+H 3 \backsim E F 1-a+U B Q \backsim E F 1-a+H 3+U B Q \backsim A C T B \backsim G A D P H$

\begin{tabular}{cccccccccc}
\hline & $E F 1-a$ & $E I F 4 A$ & $H 3$ & $U B Q$ & $E F 1-a+H 3$ & $E F 1-a+U B Q$ & $E F 1-a+H 3+U B Q$ & $A C T B$ & $G A D P H$ \\
\hline SS value & 0.1716 & 0.0474 & 0.1438 & 0.2341 & 0.0461 & 0.0349 & 0.0130 & 5.5563 & 10.9609 \\
\hline
\end{tabular}

B

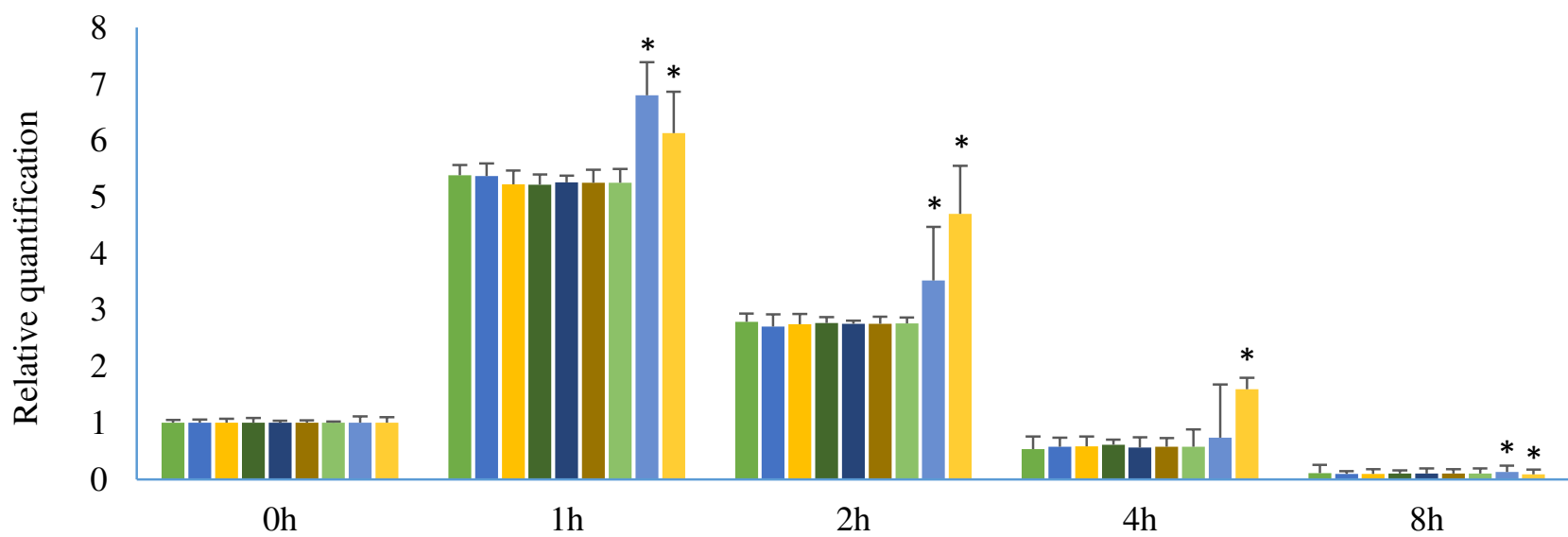

$\square E F 1-a \square E I F 4 A \square H 3 \backsim U B Q \square E F 1-a+H 3 \backsim E F 1-a+U B Q \backsim E F 1-a+H 3+U B Q \backsim A C T B \backsim G A D P H$

\begin{tabular}{cccccccccc}
\hline & $E F 1-a$ & $E I F 4 A$ & $H 3$ & $U B Q$ & $E F 1-a+H 3$ & $E F 1-a+U B Q$ & $E F 1-a+H 3+U B Q$ & $A C T B$ & $G A D P H$ \\
\hline SS value & 0.0096 & 0.0140 & 0.0033 & 0.0058 & 0.0008 & 0.0009 & 0.0004 & 2.9290 & 5.5578 \\
\hline
\end{tabular}

